NBER WORKING PAPER SERIES

\title{
The Welfare Cost of Social Security's Impact on Private Saving
}

Martin Feldstein

Working Paper No. $\underline{969}$

\author{
NATIONAL BUREAU OF ECONOMIC RESEARCH \\ 1050. Massachusetts Avenue \\ Cambridge MA 02138
}

August 1982

\begin{abstract}
The research reported here is part of the NBER's research program in Pensions. Any opinions expressed are those of the author and not those of the National Bureau of Economic Research.
\end{abstract}


NBER Working Paper \# 969

August 1982

ABSTRACT

The Welfare Cost of Social Security's Impact on Private Saving

Although there have been several studies of the effect of social security on private saving, there has been no attempt to measure the welfare cost of this distortion. The present paper develops an analytic framework for this evaluation and presents numerical calculations.

Martin Feldstein

National Bureau of Economic Research 1050 Massachusetts Avenue Cambridge, Massachusetts 617-868-3905 


\title{
The Welfare Cost of Social Security's Impact on Private Saving
}

\author{
Martin Feldstein*
}

In recent years a substantial number of econometric studies have examined the effect of social security retirement pensions on the level of private saving. ${ }^{1}$ Implicit in these studies is the presumption that reduced saving implies a welfare cost. It is surprising therefore that there have been no explicit attempts to evaluate the size of this welfare cost in a manner analogous to the measurement of the welfare cost of distortionary taxes (e.g., Harberger 1964 and the studies cited in Atkinson and Stiglitz, 1980). The purpose of the present study is to provide such an evaluation.

The analysis here shows that in an important special case a social security program can reduce private saving without imposing any welfare loss. In more realistic cases, however, the welfare loss is large both absolutely and in relation to the size of the social security program.

The primary rationale for universal social security pensions is of course to provide retirement income to those who lack the foresight to provide for themselves. An evaluation of the net effect of social security therefore requires balancing the welfare gain from this type of transfer payment against the welfare loss caused by the savings distortion. A more complete analysis would also include the distortion in retirement behavior and in pre-retirement labor supply caused by social security taxes and benefits. An evaluation of

*Harvard University and the National Bureau of Economic Research. This paper is part of the NBER Study of Public and Private Pensions. The views expressed here are the authors and should not be attributed to any organization.

${ }^{1}$ E.g., Barro (1979), Barro and MacDonald (1979), Blinder, Gordon and Wise (1980), Darby (1979), Diamond and Hausman (1982), Feldstein (1974, 1977, 1980, 1982), Feldstein and Pellechio (1979), Kotlikoff (1979), and Munnell (1976). 


\section{$-2-$}

the welfare loss of the induced reduction in savings is however a useful starting place and a natural sequel to the econometric studies of the effect of social security on saving.

The present paper therefore makes the extreme assumption that labor supply and retirement behavior are exogenously fixed and that each dollar of "social security wealth" (i.e., the present value of social security benefits) reduces private saving by one dollar. The latter assumption implies that social security does not raise consumption during retirement. I want to emphasize that this extreme assumption is not meant to represent reality ${ }^{1}$ but to focus the analysis on the welfare cost of reduced capital accumulation.

The reduction in private saving could, of course, be offset or more than of set by accumulating a large trust fund with which to pay future social security benefits (Samuelson, 1975; Feldstein 1977). In practice, however, the social security program in the United States and in most other industrial countries is unfunded. I shall therefore assume that there is no funding and no change in other public capital accumulation to offset the reduction in private capital accumulation.

The first section of this paper develops the analytic framework for evaluating the net loss of reduced private saving. The second section presents some illustrative numerical calculations. Then in the third section I examine the effect of a finite horizon on the value of the welfare loss. There is a brief concluding section that indicates the direction for future research on this subject.

$I_{\text {Empirical estimates of the extent to which social security benefits reduce }}$ private saving vary but most of the estimates indicate that each dollar of social security wealth reduces private wealth accumulation by between 50 cents and one dollar. 


\section{$-\overline{-}$}

1. The Analytic Framewor.

In a very important paper, Paul Samuelson (1958) extended the life cycle theory by developing an explicit overlapping generations model and used this framework to analyze the effect of social security. Since Samuelson assumed an economy without a productive capital stock or other durable store of value, social security could play the welfare-increasing role of permitting individuals to finance retirement consumption.

The absence of a capital stock is of course critical to Samuelson's conclusion that an unfunded social security program increases the welfare of all generations. In a model with a productive capital stock, the substitution of unfunded social security for private saving raises the welfare of all generations only if the economy is initially producing with an inefficiently large capital stock. ${ }^{1}$ When this is not true, the excess of the productivity of real capital over the implicit rate of return earned on the taxes paid to an unfunded social security program causes a loss to each generation of workers who participate in the program. Since members of the initial generation of retirees receive benefits without paying any taxes, their welfare is unambiguously increased. The net welfare effect depends on balancing the gain to the first generation of retirees against the loss to all future generations.

The framework for the present analysis will be an extended version or Samuelson's overlapping generations model. Each individual lives for two periods, working in the first period and retiring in the second period. All

${ }^{1}$ Cass and Yaari (1967) show that if the economy's rate of growth exceeds its marginal product of capital, the substitution of social security for private saving raises welfare in all generations. This is an application of the familiar proposition that welfare can be unambiguously improved by reducing capital intensity in an economy whose capital intensity is greater than the golden rule level. Samuelson's economy without productive capital is a special case of the growth rate exceeding the productivity of capital. 
individuals are alike and earn a wage $w_{t}$ if they work in period $t$. The labor force grows at rate $\mathrm{n}$ per period and the real wage rate grows at rate $g$ per period. The basic difference from the Samelson model is that savings may be invested in real capital. To avoid the complexities of an endogenous and timevarying rate of return, I shall assume that the marginal product of capital remains constant at rate $\rho$ per period.

The number of aged retirees in each period $\left(A_{t}\right)$ is equal to the number of workers in the previous period $\left(L_{t-1}\right)$. Since the population grows at rate $n$ per period, $L_{t}=(1+n) L_{t-1}$ and $L_{t}=(1+n) A_{t}$.

Consider a social security program that imposes a tax at rate $\theta$ on wage income in each period. The workers in period $t$ pay a tax of $T_{t}=\theta_{w_{t}} L_{t}$ and, because of the unfunded pay-as-you-go nature of the program, receive benefits when they retire equal to the taxes paid by the next generation: $B_{t+1}=b_{t+1} A_{t+1}=\theta_{w+1} L_{t+1}$ where $b_{t}$ is the benefit per retiree in period t.

The implicit rate of return, $\gamma$, that individuals earn on their tax "contributions" is defined by the ratio of the benefits that they receive to the taxes that they previously paid: $B_{t+1} / T_{t}=\theta_{w+1} L_{t+1} / \theta_{w_{t}} L_{t}=(1+g)(1+n)=1+\gamma$ since $I+n=I_{t+1} / L_{t}$ and $l+g=w_{t+l} / w_{t}$. The implicit rate of return is therefore equal to the rate of growth of real income.

If the workers of generation $t$ had instead saved and invested $T_{t}$, their savings would have earned the real marginal product of capital, $\rho$. If there were no tax on capital income, the individual savers would also receive a return of $\rho$. But even if a capital income tax reduces the net return to individual savers, the nation as a whole earns the entire pretax rate of return. I 
shall assume that the benefits of that tax revenue accrues to the generation of savers who own the capital. ${ }^{1}$ Thus instead of receiving $B_{t+1}=(1+\gamma) T_{t}$ in return for their social security taxes, they would receive $(1+\rho) T_{t}$. The social security program therefore reduces the retirement incone of the workers of period $t$ by $(\rho-\gamma) T_{t}=(\rho-\gamma) \theta_{w_{t}} L_{t}$

The present value of this loss as of the first period of these worker's lives is $(p-\gamma) \theta_{w_{t}} L_{t} /(I+d)$ where $d$ is the rate at which individuals discount income between the two periods. If there is no capital income tax, individuals equate their rate of time preference to the marginal product of capital: $d=\rho$. A capital income tax at rate $t$ lowers the annual marginal rate of return to individual savers ${ }^{2}$ from $r$ to $(1-t) r$ and therefore makes the net rate of return per period $P_{\mathrm{N}}=[1+(1-t) \mathrm{r}]^{\mathrm{y}}-1$ where $\mathrm{y}$ is the number of years in a generation. I shall define an effective "period tax rate" $\tau$ by the identity $\rho_{N}=(1-\tau) \rho$. Thus, with a capital income tax, the equality of the individuals' time preference and the net rate of return implies $d=(1-\tau) \rho$.

In the next generation the corresponding loss is $(\rho-\gamma) \theta_{t} w_{t+1} L_{t+1} /(1+d)=(\rho-\gamma) \theta(1+g) w_{t}(I+n) L_{t} /(1+d)=(1+\gamma)(\rho-\gamma) \theta_{w_{t}} L_{t} /(1+d)$. Thus the generational loss grows at rate $\gamma$. If the program is introduced with workers of generation $t=0$ and continues forever, ${ }^{3}$ the present value of the infinite stream of losses is given by

$$
Z=\sum_{t=0}^{\infty} \frac{(p-\gamma) \theta w_{t} L_{t}}{(1+d)(1+\delta)^{\tau}}
$$

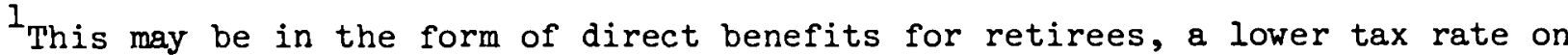
capital income, or an equivalent reduction in the labor income tax. If instead the revenue is used to reduce the tax burden on the next generation of workers, the analysis would differ only slightly from the one that follows in the text.

${ }^{2}$ A capital income tax reduces the marginal return to individual savers even though the total return to savers as a whole is $p$.

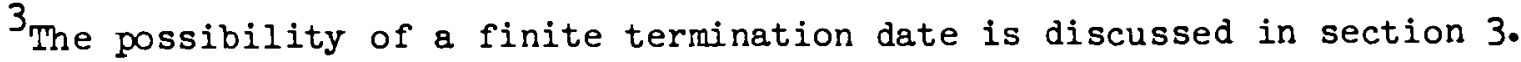


where $\delta$ is the appropriate discount rate for the intergenerational aggregation of consumption. ${ }^{1}$ since $w_{t} L_{t}=(1+g)^{t} w_{0}(1+n)^{t} L_{0}=(1+\gamma)^{t} w_{0} L_{0}$,

$$
Z=\frac{(\rho-\gamma) \theta_{w_{O}} L_{O}}{1+d} \sum_{t=0}^{\infty}\left[\frac{1+\gamma}{1+\delta}\right]^{t} .
$$

If the discount rate exceeds the growth rate $(\delta>\gamma)$, the sum converges and the present value of the losses to all generations of workers is:

$$
z=\left[\begin{array}{ll}
1+\delta & \frac{\rho-\gamma}{\delta-\gamma}
\end{array}\right] \theta_{w_{O}} L_{0} \cdot
$$

Although $\mathrm{Z}$ measures the loss to all generations of workers who participate in the program, it ignores the benefit to the initial generation of retirees who receive benefits without paying any tax. Their benefits are equal to the taxes paid by the first generation of workers, $\theta_{W_{0}} L_{0} \cdot$ The present value net loss to all generations, including the first generation of retirees, is thus

$$
\begin{aligned}
N & =Z-\theta_{w_{O} L_{O}} \\
& =\left[\frac{1+\delta}{1+d} \cdot \frac{\rho-\gamma}{\delta-\gamma}-1\right] \theta_{w_{O} L_{O}} .
\end{aligned}
$$

The value of $N$ depends critically on the value of $\delta$, the social discount rate used for the intergenerational aggregation of consumption. There are two alternative theories of the appropriate definition of $\delta$. The first theory equates the social intergenerational discount rate with the private intrageneration discount rate, i.e., $\delta=\mathrm{d}$. The rationale for this approach is

\footnotetext{
${ }^{1}$ I shall return directly to the appropriate value of $\delta$.
} 
that the generations are linked by bequests and that the preferences of the bequethers are accepted as normatively valid. The alternative theory rejects the private discount rate as irrelevant for intergenerational comparisons and bases the social discount rate on the presumed decline in the marginal utility of income as the level of income grows. If per capita income grows at rate $g$ and the elasticity of the individual marginal utility function is $\varepsilon$, the marginal rate of substitution of income in successive periods is $(1+g)^{\varepsilon}$. Conventional assumptions put $\varepsilon$ between 1 and $3 .^{1}$

Consider first the implication of equating the social discount rate and the private discount rate, $\delta=d$. In an economy with no capital income tax, the private discount rate should equal the marginal product of capital; thus $d=\rho$ and therefore $\delta=\rho$. Substituting these values into equation 4 implies $N=0$. Thus there is no net excess burden caused by the reduction in private saving if the economy has no capital income tax (or other savings distortion) and if the marginal product of capital is used to discount future income reductions. ${ }^{2}$ In this unique case, the benefit to the initial generations of retirees who receive the unrequited transfer when the program is established just balances the infinite stream of losses sustained by all future generations.

If we continue to accept the equality of the social discount rate and the private discount rate but recognize the existence of a capital income tax, the welfare neutrality of the savings reduction disappears. With $\delta=d=(1-\tau) \rho$,

${ }^{I}$ Irving Fisher (1892) and Ragnar Frisch (1932) purported to estimate $\varepsilon$ by imposing certain separability assumptions and obtained $\varepsilon=2$.

2 This conclusion also rests on the assmption that changes in the rate of saving do not alter the marginal product of capital on the marginal rate of substitution. 
equation 4 implies $^{1}$

$$
\begin{aligned}
N & =\left[\frac{\rho-\gamma}{(1-\tau) \rho-\gamma}-1\right] \theta_{w_{O} L_{O}} \\
& =\frac{\tau \rho}{(1-\tau) \rho-\gamma} \quad \theta_{w_{O}} L_{O} \cdot
\end{aligned}
$$

It is clear that $N$ is an increasing function of the tax rate, the marginal product of capital and the economy's rate of growth. A positive capital income tax rate implies that the marginal product of capital exceeds the rate of time preference and therefore that any change in the rate of saving has a first-order welfare effect. ${ }^{2}$ The higher the marginal product of capital, the greater the welfare loss from any reduction in saving. A higher rate of growth of the economy means that the annual losses grow at a faster rate and therefore have a greater present value.

The net value presented in equation 4 can also be interpreted as the net gain of terminating an existing program in any year. Terminating the program implies that the retirees in the terminal period receive no benefits while the workers in that period and all future periods pay no tax and receive no benefits. If the terminating period is defined to be $t=0$, the net present value (as of $t=0$ ) of the welfare gain of termination is measured by $N$ with $\theta_{0} L_{O}$ the amount of tax that would be collected in that period if the program were not terminated.

$I_{\text {Recall that }} \tau$ is defined so that $(1-\tau) \rho$ is the after-tax rate of return per period.

2 This is analogous to the fact that any tax change has a first-order welfare effect if there is a pre-existing distortionary tax. 
Although the absolute present value measure is directly relevant for assessing the desirability of starting or terminating a social security program, it is also interesting to restate this loss as a proportion of the present value of all taxes. ${ }^{l}$ Since taxes at $t=0$ are $\theta_{w_{0}} L_{O}$ and benefits grow at rate $\gamma$ per period, the present value of taxes, discounting at rate $\delta$, is

$$
V=\frac{l+\delta}{\delta-\gamma} \quad \theta_{W_{0}} L_{0}
$$

The ratio of the net loss to this present value of taxes is therefore

$$
\frac{N}{V}=\frac{(1+\delta)(\rho-\gamma)-(1+\alpha)(\delta-\gamma)}{(1+\alpha)(1+\delta)(\delta-\gamma)}
$$

In the important special case where the private and social discount rates are equal $(\delta=d)$, this implies

$$
\frac{N}{V}=\frac{\rho-\delta}{1+\delta}
$$

It is interesting to compare this to the net loss to a typical worker per dollar of his tax payments. Since he receives a return of $\gamma$ on his social security taxes rather than the total return of $\rho,{ }^{2}$ his loss is $\rho-\gamma$. This loss is a reduction in his retirement income. Its present value as of the time that he works and pays tax is therfore $(\rho-\gamma) /(1+\rho)$. Since $\gamma>\delta$ is a necessary ${ }^{1}$ Note that since taxes and benefits are equal in each period, the present
value of taxes is also the present value of benefits.

${ }^{2}$ Recall that individuals may only receive the net-of-tax return $(I-\tau) \rho$ directly but also get the benefit of the tax revenue to indirectly. 
condition for the convergence of $N$ and $V$, it is clear that $N / V$ is smaller than the steady state loss per dollar of tax revenue. This difference reflects the fact that $\mathrm{N} / \mathrm{V}$ incorporates the extra benefit to the initial generation of retirees.

When the social and private discount rates are equal to the net-of-tax rate of return, $(1-\tau) \rho$, equation 7 can be written

$$
\frac{N}{V}=\frac{\tau \rho}{1+(1-\tau) \rho}
$$

The net loss per present value dollar of social security taxes is equal to the tax revenue that is lost per dollar of foregone savings, discounted at the individual's net of tax return.

\section{Some Illustrative Calculations}

Some numerical calculations will indicate plausible magnitudes for the welfare losses derived in the previous section. To obtain values for $\gamma, \rho$ and $\tau$, I will use the experience of the U.S. economy in the three decades beginning in 1950. I will assume that the length of a "period" or generation is 30 years. During the thirty years beginning in 1950, the average annual rate of growth of real personal income was 0.037 , implying that $\gamma=(1.037)^{30}-1=$ 1.97. The average pretax marginal product of capital in the U.S. nonfinancial corporate sector was 0.114 (Feldstein, Poterba and Dicks-Mireaux, 1981), implying that $\rho=(1.114)^{30}-1=24.50$. Finally, during the same period these corporations, their shareholders and their creditors paid approximately 68 percent of their pretax capital income in taxes to federal, state and local governments (Feldstein, Poterba and Dicks-Mireaux, 1981). Since this average tax rate 
may exceed the corresponding marginal tax rate, I will make the conservative assumption that $t=0.50$. With $r=0.114$ and $t=0.50,(1-\tau) \rho=\left[1+(1-t)^{r}\right]^{30}-1=4.28$. Since $\rho=24.50, \tau=0.825$.

Substituting these values into equation 5 (based on the assumption that the social and private discount rates are equal to each other and to the net-of-tax return, $(1-\tau) \rho)$ implies that the net loss is $N=8.75 \theta_{w_{0}} L_{0}$. The net welfare loss caused by the reduction in saving induced by the social security program is equal to 8.75 times the initial size of the program, i.e., 8.75 times the unrequited benefits received by the first generation of retirees. Alternatively, this calculation implies that reducing the existing social security program by a fraction $f$, and thereby denying benefits of $f \theta_{T} L_{T}$ to the

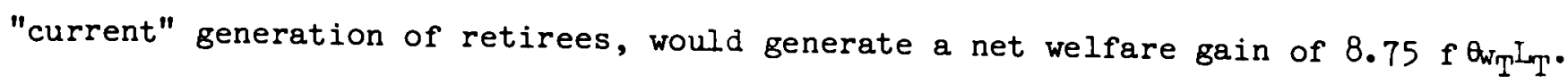

These losses and potential gains can be restated as a proportion of the present value of social security taxes by using equation 9 . With $\tau p=20.21$ and $(1-\tau)_{p}=4.28$, equation 9 implies $N / V=3.83$; the net loss is 3.83 times the present value of the taxes. This surprisingly high ratio reflects the fact that the real pretax rate of return on the foregone investment is high relative to the discount rate and that this difference compounds substantially over the 30 year length of each period. ${ }^{1}$

Although these calculations are only illustrative, the parameter assumptions are not unrealistic and the derived values of $N$ and $N / V$ do indicate the substantial size of the potential welfare loss caused by the reduced savings that result from starting or continuing an unfunded social security pension program.

\footnotetext{
${ }^{1}$ Reducing the length of the period to 20 years lowers $N$ and $N / V$ but their values remain high: $N=5.86 \theta_{w_{0}} L_{0}$ and $N / V=1.86$.
} 
If we reject the assumption that the social discount rate is necessarily equal to the private discount rate and instead use the assumed diminishing marginal utility of consumption to calculate $\delta$, we obtain $\delta=(1+g)^{\varepsilon}-1$ where $g$ is the rate of growth of per capita real income and $\varepsilon$ is the elasticity of the marginal utility schedule. During the three decades after 1950, the annual rate of growth of real per capita income was 0.023 . Thus $1+g=$ $(1.023)^{30}=1.98$. It is clear from equation 2 that convergence to a finite value of $N$ requires $\delta>\gamma=1.97$ and therefore $\varepsilon>1.6$.

With $\varepsilon=2, \delta=2.92$. Equation 4 implies that with $\delta=2.92$ and $d=$ $(1-\tau) \rho=4.28, N=16.61 \theta_{W_{O}} L_{O}$, substantially greater than the value of $N$ obtained by assuming that $\delta=(1-\tau) \rho$. Similarly $N / V=4.24$ is larger than it was with the higher discount rate. To reduce $N$ to $8.75 \theta_{w_{0}} L_{0}$, $\delta$ must be equal to $(1-\tau) \rho=4.28$. Since $(1+\delta)=(1+g)^{\varepsilon}$, the elasticity of the marginal utility function must be at least 2.45 .

Thus, both approaches to the selection of a discount rate indicate a very substantial value for the net welfare loss.

\section{Finite Horizons}

The derivations and calculations in section 1 and 2 all assume that the social security program goes on forever. There is never a "last generation" that pays a social security tax but receives no benefit. In Samuelson's words, social security is "a Ponzi game that works," 1 at least in the sense that it continues to command political support even if each new generation incurs a

${ }^{1}$ Ponzi was a famous Boston swindler whose chain letter scheme collapsed when further buyers cound not be found. 
welfare loss. ${ }^{1}$

It is important, however, to consider whether the qualitative results and the general order of magnitude of the losses depends critically on the assumption of an infinite horizon. As I noted earlier, terminating the program in year $T$ involves a net gain that is exactly equal in magnitude to the net loss implied by starting a program in that period, say

$$
G_{T}=\frac{\tau \rho}{(1-\tau) \rho-\gamma} \quad \theta_{W_{T}}{ }^{L_{T}}
$$

in the special case in which $d=\delta=(1-\tau) \rho$. The present value of this termination gain (as of time $t=0$ ) must be offset against the loss calculated for the infinite horizon.

The present value of $G_{T}$ as of time zero is $G=(1-\delta)^{-T} G_{T}=(1+(1-\tau) \rho)^{-T} G_{T}$. Thus:

$$
G=(1+(1-\tau) \rho)^{-T} \frac{\tau \rho}{(1-\tau) \rho-\gamma} \quad \partial_{w_{O}} L_{0}(1+\gamma)^{T}
$$

or

$$
G=\left[\frac{1+\gamma}{1+(1-\tau) \rho}\right]^{T} N
$$

Since $\gamma<(1-\tau) \rho$, the offsetting gain is of decreasing relative importance as $T$ increases.

If there wers only two generations, the workers would vote to terminate the program and, because they are more numerous, would prevail. In reality, there is a distribution of ages and some of those who are not yet retired would be net losers if the program were terminated. The redistribution in the actual program further complicates the voting equilibrium. See Feldstein and Pellechio (1979b) for a brief discussion of these issues and some empirical estimates. 
If, for example, the program is terminated after 3 generations ( 90 years), $G=0.18 \mathrm{~N}$. The present value loss of a program that lasts three generations is thus 82 percent of the loss of an infinite program.

For plausible parameter values, the assumption of an infinite horizon does not alter the qualitative or general quantitative conclusions.

\section{Conclusion}

The analysis and calculations presented in this paper make it clear that a social security program that replaces an equal amount of private saving can impose a welfare loss whose present value is many times the size of the existing generation's benefit. The actual adverse welfare effect depends, of course, on the extent to which social security benefits do depress private saving as well as on the effect of social security programs on labor supply, retirement behavior, etc. Moreover, because some individuals behave myopically, the social security program not only reduces saving by less than the full amount of taxes but also provides income to those who might otherwise have too little in old age.

Evaluating the magnitude of the welfare loss caused by reduced saving is therefore just one part of the evaluation of the welfare effect of social security. A similar analysis is required to evaluate the effects of changes in retirement and labor supply. These adverse consequences must then be balanced against the favorable effect of providing retirement income for those who lacked the foresight to provide for themselves. The net welfare effect of variations from the current level of benefits could then be assessed as a basis for deciding the appropriateness of changing the existing program. 
Atkinson, A. and J. Stiglitz (1980) Lectures on Public Economics, New York: McGraw-Hill

Barro, R.J. (1978) The Impact of Social Security on Private Saving, Washington: American Enterprise Institute.

Barro R. and G. MacDonald, (1979) "Social Security and Consumer Spending in an International Cross-Section," Journal of Public Economics.

Blinder, A., R. Gordon and D. Wise, "Life Cycle Savings and Bequests: Crosssectional Estimates of the Life Cycle Model," in The Determinants of National Savings and Wealth, edited by Franco Modigliani, London and New York: Macmillan, in press.

Cass, D. and M. Yaari, (1967) "Individual Savings, Aggregate Capital Accumulation, and Efficient Growth," in K. Shell, (ed.) Essays on the Theory of Optimal Economic Growth, Cambridge, MA: MIT Press, 233-268.

Darby, M.R. (1979) The Effects of Social Security on Income and the Capital Stock, Washington: American Enterprise Institute.

Diamond P.A. and J. Hausman (1982) "Individual Retirement and Savings Behavior Decisions," presented at the Oxford Conference on Microdata and Public Economics, June 27-30, 1982.

Feldstein M. (1974) "Social Security, Induced Retirement, and Aggregate Capital Accumulation," J.P.E. 82, 905-26.

(1977) "The Social Security Fund and National Capital Accumlation," Funding Pensions: The Issues and Implications for Financial Markets, a Federal Reserve Bank of Boston publication.

(1977) "Social Security" and Private Savings: International Evidence in an Extended Life Cycle Model," in The Economics of Public Services, M. Feldstein and R. Inman (eds.), London: Macmillan.

(1980) "International Differences in Social Security and Saving," Journal of Public Economics: $14,225-44$.

(1982) "Social Security and Private Saving: Reply" Journal of Political Economy: $90,630-642$.

Feldstein, M. and A. Pellechio (1979a) "Social Security and Household Wealth Accumulation: New Microeconomic Evidence" Review of Economics and Statistics: $61,361-68$.

Feldstein, M. and A. Pellechio (1979b) "Social Security Wealth: The Impact of Alternative Inflation Adjustments" in C. Campbell, (ed.), Financing Social Security. 
Feldstein, M., J. Poterba and L. Dicks-Mireaux (1981) "The Effective Tax Rate and the Pre-Tax Rate of Return," NBER Working Paper No. 740, Journal of Public Economics, forthcoming.

Fisher, I. (1892), Mathematical Investigations in the Theory of Value and Prices, Connecticut Academy of Arts and Sciences.

Frisch, R. (1932), "New Methods of Measuring Marginal Utility," in Beitrage zur okonomischen Theorie (No. 3), Tubigen: J. C. B. Mohr.

Harberger A.C. (1964) "Taxation, Resource Allocation, and Welfare" in J. Due (ed.) The Role of Direct and Indirect Taxes in the Federal Revenue System, Princeton Univertsity Press, Princeton, New Jersey•

Kotlikoff, L. J. (1979) "Testing the Theory of Social Security and Life Cycle Accumulation," American Economic Review 69, 396-410.

Munnell, A. H. (1974) The Effect of Social Security on Personal Saving, Cambridge, Mass.: Ballinger.

Samuelson, P. A. (1958) "An Exact Consumption-loan Model of Interest with or Without the Social Contrivance of Money" Journal of Political Economy, 66, $467-482$.

Samuelson, P. A. (1975) "Optimal Social Security in a Life-cycle Growth Model", International Economic Review, 16, 539-544. 